\title{
ANALYSIS OF WHEAT CROP FORECASTS, IN INDIA, GENERATED USING REMOTE SENSING DATA, UNDER FASAL PROJECT
}

\author{
Santosh Kumar*, Shalini Saxena, S.K. Dubey, Karan Chaudhary, Seema Sehgal, Neetu and S. S. Ray \\ Mahalanobis National Crop Forecast Centre, DAC\&FW, New Delhi - (im2skumar, saxenaorshalini9, sunil2949, karanknit, \\ seemasehga193, rathineetu, shibendu.ray)@gmail.com
}

Commission III, WG III/10

KEY WORDS: FASAL, DES, NDVI, VCI, Weather data, Wheat, Resourcesat-2, Landsat-8, Sentinel-2, Yield

\begin{abstract}
:
Wheat (Triticum aestivum L.) is a major cereal crop of the world, which plays an important role in global food and nutritional security. In India, wheat grown areas are more as compared to other food crops, except for rice. The total area under wheat cultivation is 30.60 million hectares with production of 98.38 million tonnes and the productivity is 3.22 tonnes /hectare (DES, 2017). The main objective of this paper is to highlight the development of satellite-based methodology, compare the relative deviations (\%) at national level, RMSE (\%) and correlation coefficient at state level and correlation coefficient at district level between DES and FASAL estimates from 2013 to 2017. It was observed that the area and production estimates improved with improvement in the satellite resolution and ground truth data. During the last 10 years of estimation the spatial resolution of the satellite data has gradually improved from 23.5 meter of (Reourcesat-2, LISS-III) and finally $10 \mathrm{~m}$ of Sentinel-2, MSI, which is being currently used for acreage estimation purpose. Hooda R.S et al (2006) studied that the improvement in the spatial resolution, spectral and temporal resolution of the satellite data has also improved the crop discrimination. Both accuracy as well as precision of the estimates has improved over the years from 2013 to 2017, as reflected by relative deviation, RMSE (\%) and Coefficient of correlation values at national, state and district level respectively.
\end{abstract}

\section{INTRODUCTION}

With growing population and increasing demands for food and security, wheat (Triticum aestivum L.) plays as a major role in global food and nutritional security and grown on more land area than any other food crop (220.4 million hectares, FAOSTAT 2014) and 749 million tonnes wheat is produced in 2016 (FAO, 2016), makes it the second most-produced cereal after maize. India produces $13.1 \%$ of the total wheat production of the world, occupying the second position, next to China. About 40 per cent of the total food grain reserves of the country is contributed by wheat crop. The total area under wheat cultivation is 30.60 million hectares with production of 98.38 million tonnes and the productivity being 3.22 tonnes/hectare (DES, 2017). Major wheat producing states of India include Haryana, Madhya Pradesh, Punjab, Rajasthan and Uttar Pradesh. In India, the highest area and production under wheat cultivation is in Uttar Pradesh whereas, Haryana ranks first in productivity. Goswami, S.B et al (2012) has estimated district level wheat crop acreage using single date Resourcesat-1, LISSIII data and compared the deviation found from the land record data of commissioner of Madhya Pradesh. Hooda, R.S et al (2006) has studied wheat crop area and yield estimate using remote sensing data. In the present studies wheat area, was studied at National/State level during 2013 using low resolution Resourcesat-1, AWiFS data and sample segment approach under FASALSoft 1.0 and from 2014 onwards district level and Maximum Likelihood (MXL) approach was started using complete enumeration method, medium resolution Resourcesat2, LISS-III $(23.5 \mathrm{~m})$ and Landsat-8, OLI $(30 \mathrm{~m})$ and yield estimation using meteorological and remote sensing data based models. Further high-resolution Sentinel-2, MSI (10m) data was incorporated from 2016 onwards. The results obtained under FASAL were compared with DES estimates at National, State and District level.

\section{STUDY AREA}

Major wheat growing states in India are Punjab, Uttar Pradesh, Madhya Pradesh, Bihar, Rajasthan, Gujarat, Haryana, Himachal Pradesh, and Uttarakhand (Figure 1). These states contribute an aggregate of $93.1 \%$ of the total wheat area and $96.2 \%$ of total wheat production (based on DES data of 2011-12 to 2015-16) in the country. The State-wise contribution of wheat area and production of the country are shown in Figure 2. Uttar Pradesh state covers total $32 \%$ of the wheat area, while Madhya Pradesh and Punjab cover $18 \%$ and $12 \%$ of area respectively. Uttar Pradesh also occupies the first place in terms of production accounting for $30 \%$ followed by Punjab and Madhya Pradesh contributing $18 \%$ and $15 \%$ of total production, respectively. FASAL (Forecasting Agricultural output using Space, Agrometeorology and Land based observations) is the national level programme of Ministry of Agriculture and Farmers Welfare, under which MNCFC (Mahalanobis National Crop Forecast Centre) has been regularly generating crop forecasts at District/State/National level for major crops of the country since 2012.This programme includes multiple pre-harvest crop acreage and production estimation forecasts for 9 crops, i.e. Rice (Kharif \& Rabi), Wheat, Rapeseed \& Mustard, Jute, Sugarcane, Cotton, Rabi Sorghum and Pulses (Rabi).

\section{DATA USED \& METHODOLOGY}

\subsection{Satellite Data Used for Area Estimation}

Present studies have been carried out using different satellite data (multiple spatial and temporal resolution) for wheat area estimation since 2013-14. The details of the satellite/(sensor) have been shown in Table 1.

*Corresponding Author 


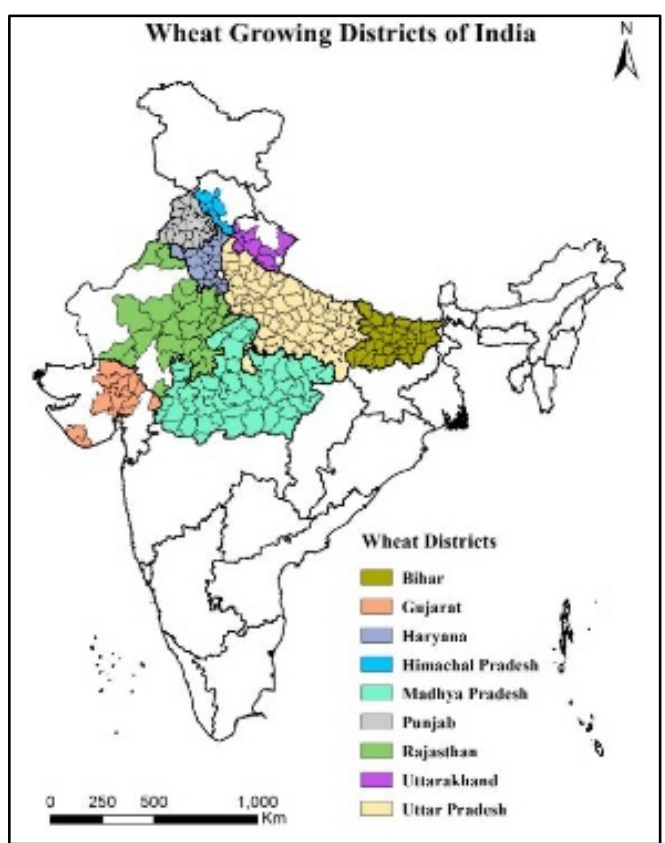

Figure 1. Major wheat growing states of India

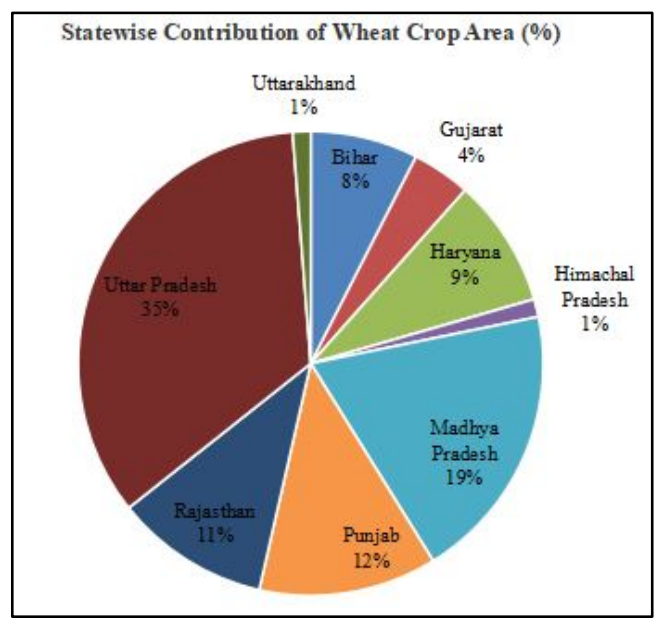

(a)

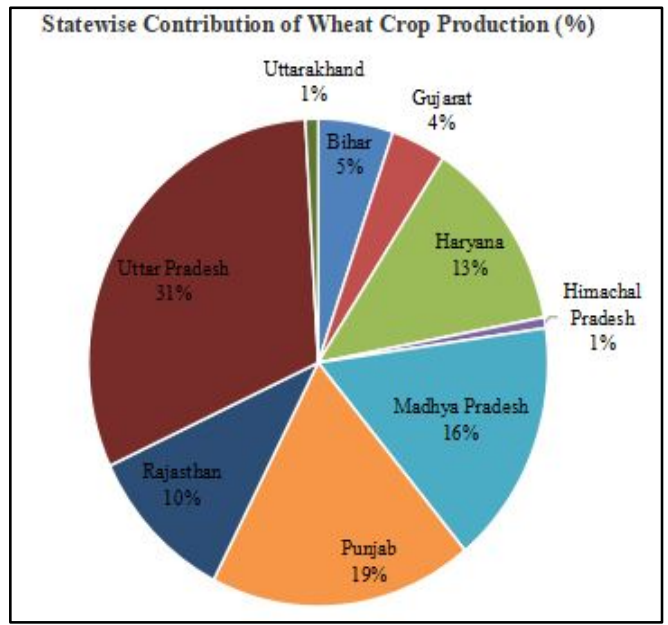

(b)
Figure 2. The State-wise(percentage) contribution of wheat area(a) and production(b)

\begin{tabular}{|c|c|c|c|c|}
\hline \multicolumn{5}{|c|}{ Remote Sensing Data/Satellite/Sensor } \\
\hline 2013 & 2014 & 2015 & 2016 & 2017 \\
\hline R2 & R2 & R2 & R2 & R2 \\
AWiFS & AWiFS & AWiFS & AWiFS & AWiFS \\
LISS-III & LISS-III & LISS-III & LISS-III & LISS-III \\
- & - & Landsat- & Landsat- & Landsat- \\
- & - & $8(\mathrm{OLI})$ & $8(\mathrm{OLI})$ & $8(\mathrm{OLI})$ \\
& & Sentinel- & Sentinel- & Sentinel- \\
& & 2 (MSI) & 2(MSI) & 2(MSI) \\
\hline
\end{tabular}

Table 1. Showing year-wise Satellite and sensor from 2013 to 2017

\subsection{Satellite Data for Yield Estimation}

\subsubsection{MODIS NDVI Data}

Moderate resolution remote sensing data of MODIS (Moderate Resolution Imaging Spectroradiometer) on-board Terra/Aqua Satellite was used for developing remote sensing based index (Vegetation Condition Index). Fortnightly MODIS Normalized Difference Vegetation Index products (250 m resolution), from 2006 were used for computing VCI, as given below.VCI can be computed as Kogan, (1997).

$$
V C I=\frac{N D V I_{\text {curr }}-N D V I_{\text {min }}}{N D V I_{\max }-N D V I_{\min }}
$$

Where, NDVICurr, NDVIMax, NDVIMin, are the values of Normalized Difference Vegetation Index values of Current period, maximum and minimum of last 11 years' data, for the corresponding period, respectively. The following set of data has been used in semi physical model.

\begin{tabular}{|c|c|c|c|}
\hline Data /Product & $\begin{array}{c}\text { Satellite/ } \\
\text { Ground }\end{array}$ & Sensor & $\begin{array}{c}\text { Resolutio } \\
\text { n }\end{array}$ \\
\hline $\begin{array}{c}\text { Daily integrated } \\
\text { Insolation }\end{array}$ & INSAT 3D & Imager & $8 \mathrm{~km}$ \\
\hline $\begin{array}{c}\text { 8-days } \\
\text { composite } \\
\text { FAPAR }\end{array}$ & Terra & MODIS & $0.5 \mathrm{~km}$ \\
\hline $\begin{array}{c}\text { 8-days } \\
\text { composite } \\
\text { surface } \\
\text { reflectance }\end{array}$ & Terra & MODIS & $0.5 \mathrm{~km}$ \\
\hline $\begin{array}{c}\text { Crop(Wheat) } \\
\text { mask }\end{array}$ & Resourcesat & AWiFS & $56 \mathrm{~m}$ \\
\hline $\begin{array}{c}\text { Daily Tmin and } \\
\text { Tmax }\end{array}$ & $\begin{array}{c}\text { Gridded Data } \\
\text { of IMD }\end{array}$ & $\begin{array}{c}0.5 \times 0.5 \\
\text { degree }\end{array}$ \\
\hline $\begin{array}{c}16 \text { days NDVI } \\
\text { Profile }\end{array}$ & Terra & MODIS & $250 \mathrm{~m}$ \\
\hline
\end{tabular}

Table 2. Showing satellite details for Yield Data. 


\subsubsection{Ground Truth Data}

Ground truth (GT) data is essential for the analysis of remote sensing data for differentiating various land uses/land covers and crop classes. The ground truth (GT) for wheat crop has been collected each year during rabi season with collaboration with State Agriculture Departments. The ground truth has been conducted for use of reference for the analysis of a remotely sensed image and to verify the accuracy of crop classification using remote sensing data (accuracy assessment). The GT data has been collected by the state agriculture department officials using a smartphone based Android App, called Bhuvan FASAL, developed by NRSC (ISRO). Number of GT collected and used from 2013 to 2017 has been shown graphically in the figure 3 (State wise (a), and total (b)).

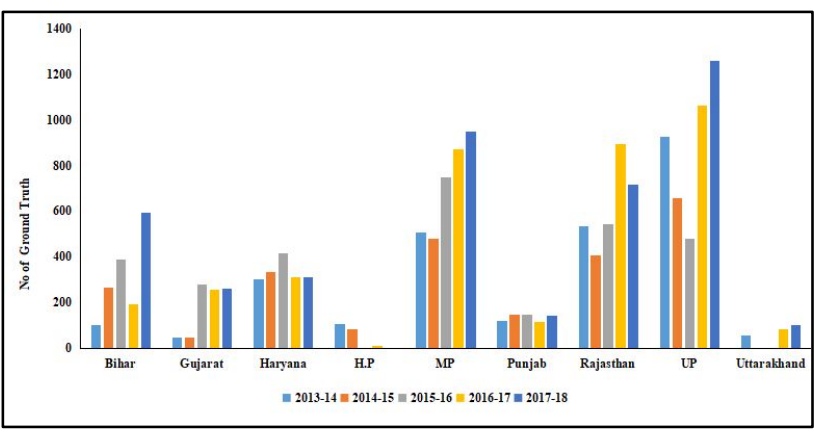

Figure 3(a). State wise GT used from 2013-14 to 2017-18

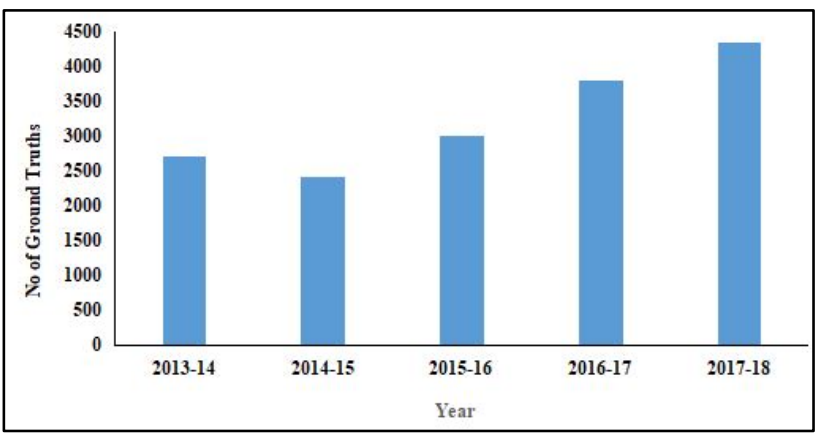

Figure 3(b). Year wise total GT used from 2013-14 to 2017-18

\subsubsection{Methodology for Area estimation}

During 2013-14 single date data (R2 AWiFS) and sample segment approach was used for state wise wheat crop estimation. From 2014-15 onwards, complete enumeration approach was used for district wise crop area estimation using single date high resolution data including Resourcesat-2 LISSIII and Landsat-8, OLI in 2014-15 along with Sentinel-2, MSI in 2016 and 2017. Wheat classification includes a two-step process comprising of optimum date selection and classification. K-means, ISODATA classification was carried out on the multi-spectral (3-4 bands) data set to identify the land use classes. Within crop classes, Maximum Likelihood Classification approach was followed using ground truth sites collected by state agricultural departments. Area of interest of wheat crop and other land cover features are identified using ground truth data. The maximum likelihood classifier was used which calculates the probability of a pixel belonging to a particular class. Lillesand and Kiefer, (2000). After the classification wheat crop mask was generated and wheat crop acreage was calculated by overlaying the district boundary.
Finally, accuracy of the classified results was verified using ground truth. Additional data used for crop classification included agricultural crop mask, collected from LULC mapping programme of NRSC (NRSC, 2006).

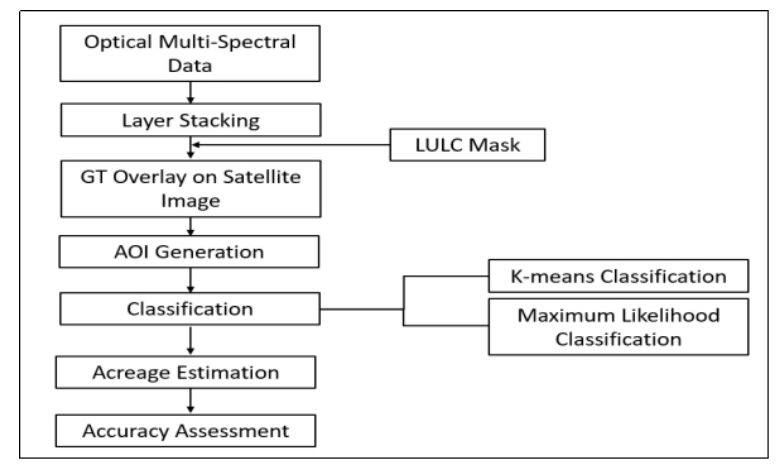

Figure 4. Shows the illustrative flow diagram of crop classification.

\subsubsection{Methodology for Yield Estimation}

Tripathy et al, (2014) has used Spectral yield models based on Vegetation Index (VI) and the mechanistic crop simulation models for estimating wheat yields. Yield has been estimated using Agro-meteorological regression models in 2012-13 and Semi-physical model using satellite derived input and weather based model in 2013-14. Crop simulation model included in 2015-16 for yield estimation and semi physical model also used for 2017-18 estimates. District level wheat crop yield has been estimated using four different procedures - i) Agrometeorological regression models, ii) Crop Simulation model iii) Remote sensing index (NDVI and VCI) based empirical models, and iv) Semi physical Model. First two approaches were used by IMD (in collaboration with state agricultural universities); The third and fourth approaches were used by MNCFC to estimate wheat yield.

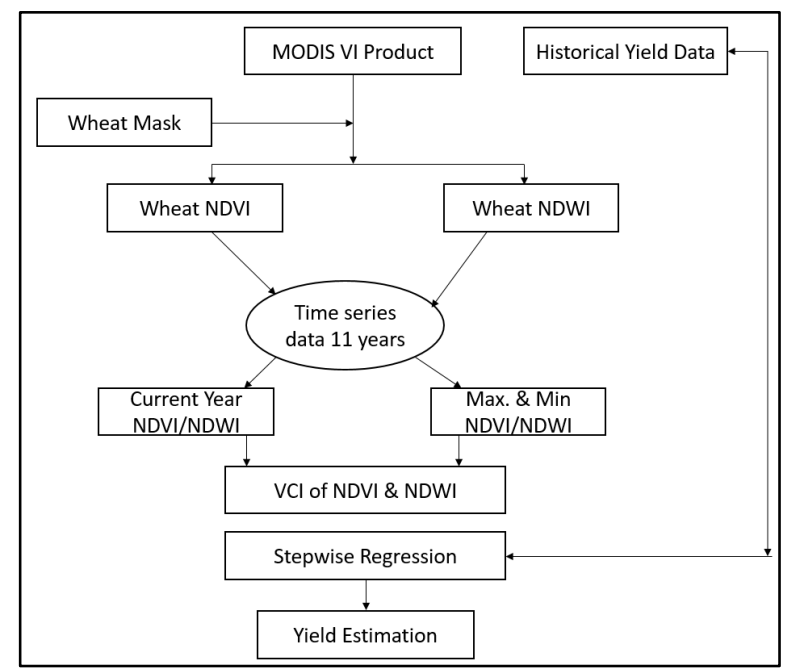

Figure 5. Flow diagram for calculation of yield using Vegetation Condition Index (VCI) (Dubey et al., 2016 


\section{RESULTS AND DISCUSSION}

\subsection{Satellite data and Classified Image}

Based on area of interest (AOI) generated using ground truth sites for wheat and mustard and crop profile generated from mean values, crops were classified using maximum likelihood classifier. An example for wheat and mustard crop classified of Baran district of Rajasthan using Sentinel-2 MSI (10m) has been shown below (Figure 6).

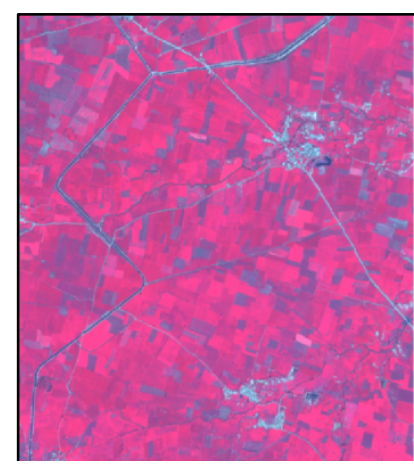

Sentinel-2, 30-January-2018

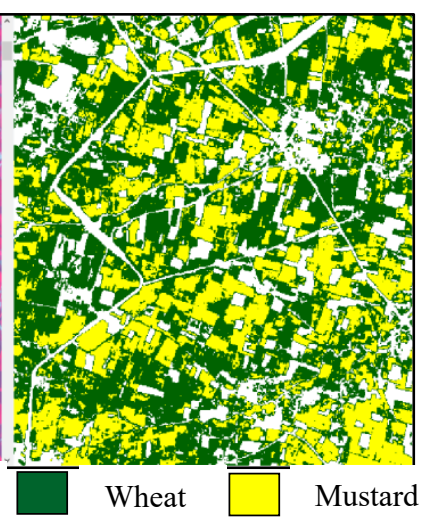

Figure 6. Showing classified image of wheat and mustard crop

\subsection{Classification Accuracy}

Accuracy of image classification is defined as a percentage correct on the basis of ground truth data at a number of locations within the image. The user's accuracy (UA) is computed using the number of correctly classified pixels to the total number of pixels assigned to a particular category. It takes errors of commission into account by telling the user that, for all areas identified, a certain percentage are actually correct. The producer's accuracy (PA) informs the image analyst of the number of pixels correctly classified in a particular category as a percentage of the total number of pixels actually belonging to that category in the image. Producer's accuracy measures errors of omission. Overall accuracy for wheat is $84.77 \%$ which has improved with the use of high resolution data for acreage estimation.

\begin{tabular}{|c|c|c|c|c|c|}
\hline \multicolumn{6}{|c|}{ Accuracy Assessment } \\
\hline \multirow{2}{*}{$\begin{array}{l}\text { Class } \\
\text { Name }\end{array}$} & \multicolumn{2}{|c|}{ Reference Classified } & \multirow{2}{*}{$\begin{array}{l}\text { Number } \\
\text { Correct }\end{array}$} & \multirow{2}{*}{$\begin{array}{l}\text { Producers } \\
\text { Accuracy }\end{array}$} & \multirow{2}{*}{$\begin{array}{c}\text { Users } \\
\text { Accuracy }\end{array}$} \\
\hline & Total & Total & & & \\
\hline Wheat & 96 & 100 & 85 & $88.54 \%$ & $85.00 \%$ \\
\hline Mustard & 55 & 51 & 43 & $78.18 \%$ & $84.31 \%$ \\
\hline \multirow[t]{3}{*}{ Totals } & 151 & 151 & 128 & & \\
\hline & \multicolumn{5}{|c|}{ Overall Classification Accuracy $=84.77 \%$} \\
\hline & \multicolumn{5}{|c|}{ Overall Kappa Statistics $=0.670$} \\
\hline
\end{tabular}

\subsection{Deviation (\%) of wheat area and production at national level}

Relative deviation (\%) of DES \& FASAL from 2013 to 2017 shows $(-3.93 \%)$ and $(-7.64 \%)$ for area and production respectively as shown in Figure 7. Singh et al, (2017) studies show low estimates for yield and production because of heavy rainfall and hailstorm events occurred in major wheat growing areas of the country during February and March 2015 that caused large scale damages to the crop.

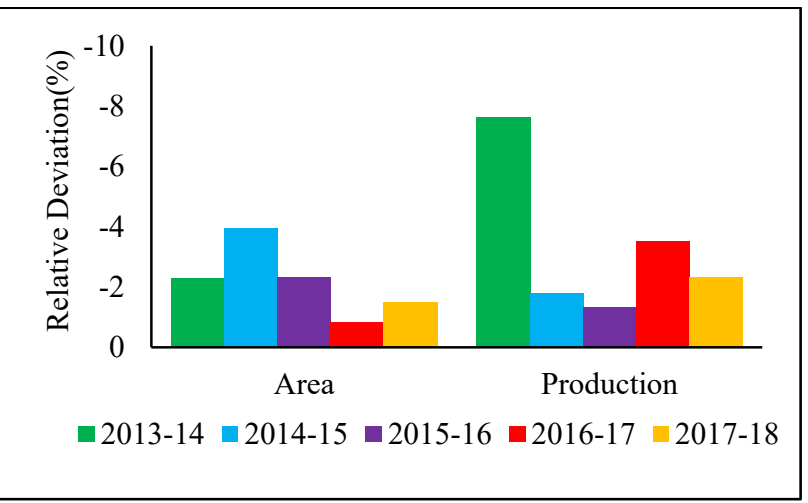

Figure 7. Showing RD (\%) of area and production from 20132017

\subsection{Comparison RMSE (\%) \& Correlation Coefficient(R)}

RMSE (\%) have improved over the years from 2015 to 2017 due to the improved satellite resolution (Sentinel-2, MSI,10m), (Table 1) and ground truth data (Figure 3b). Correlation coefficient is very high between DES and FASAL estimates of more than 0.995 (Figure 9). Similar correlation coefficient was observed for production, except for the year 2014-15 which may be because of heavy rainfall and hailstorm events occurred in major wheat growing areas of the country during February and March 2014-15 that have caused large scale damages to the crop. Singh et al, (2017).

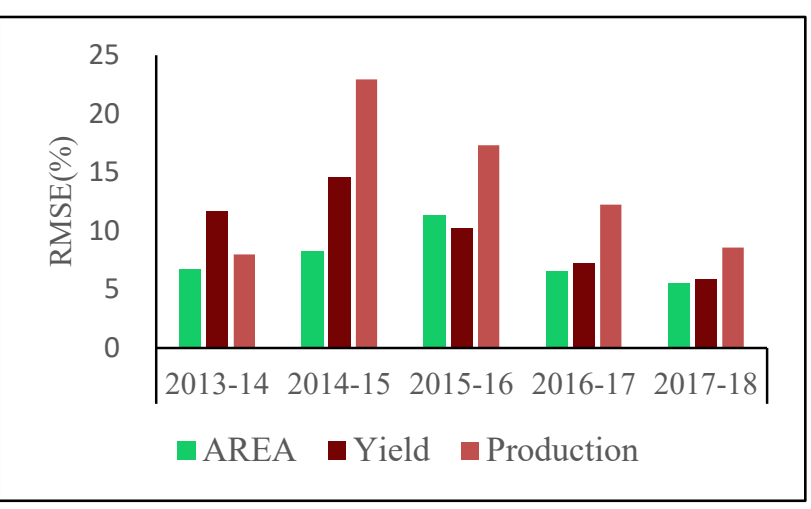

Figure 8. State-wise RMSE (\%) between DES \& FASAL State level Estimates (2013-2017)

Table 6. Accuracy assessment for wheat crop 


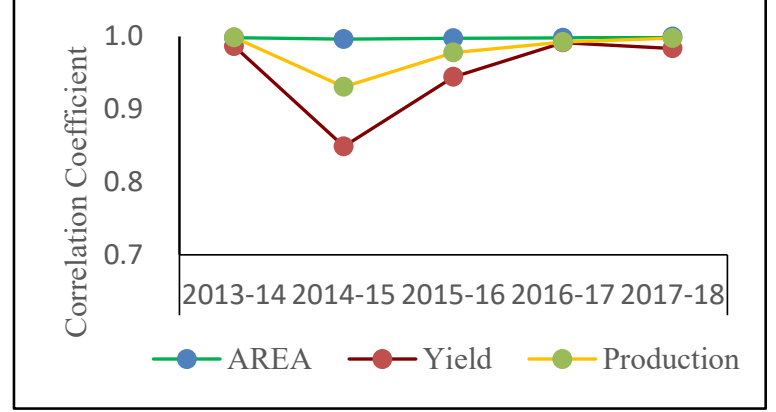

Figure 9. State-wise Correlation Coefficient between DES \& FASAL Estimates (2013-2017)

\subsection{Correlation Coefficient between DES \& FASAL estimates}

The district-wise correlation coefficients between DES \& FASAL estimates for area, yield \& production was $0.93,0.63 \&$ 0.92 respectively as predicted from Figure 9, Figure $10 \&$ Figure 11. Correlation coefficient values for yield was low may be due to heavy rainfall and hailstorm events occurred in major wheat growing areas of the country during February and March 2015.

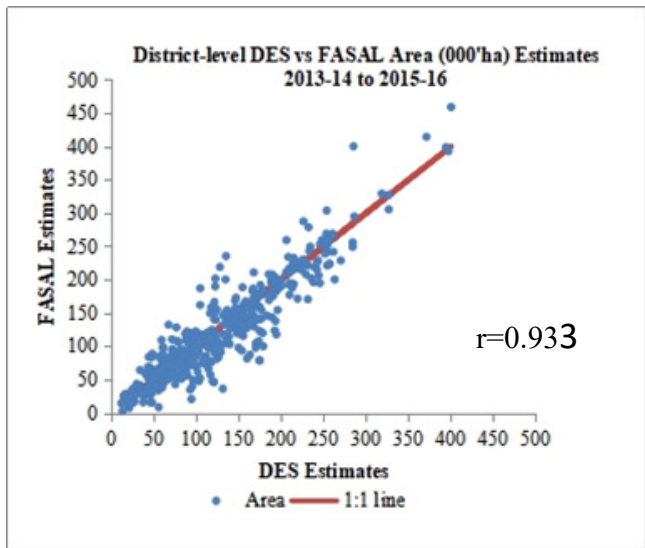

Figure 10. District-wise Area ('000 ha), DES and FASAL Estimates (2013-14 to 2015-16)

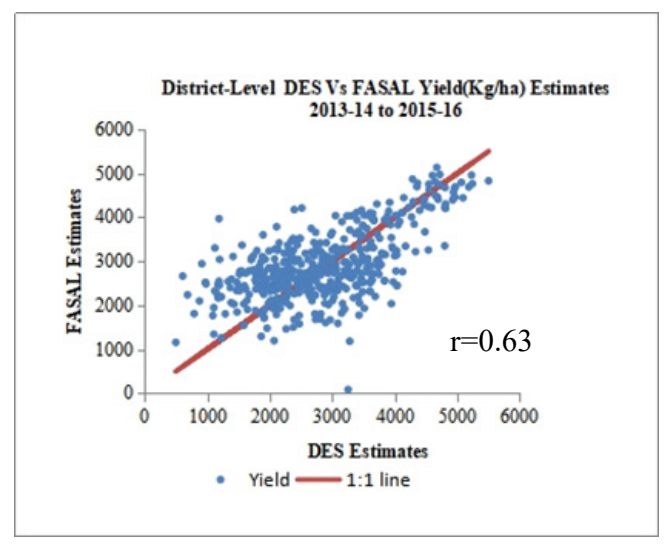

Figure 11. District-wise Yield (kg/ha), DES and FASAL Estimates (2013-14 to 2015-16)

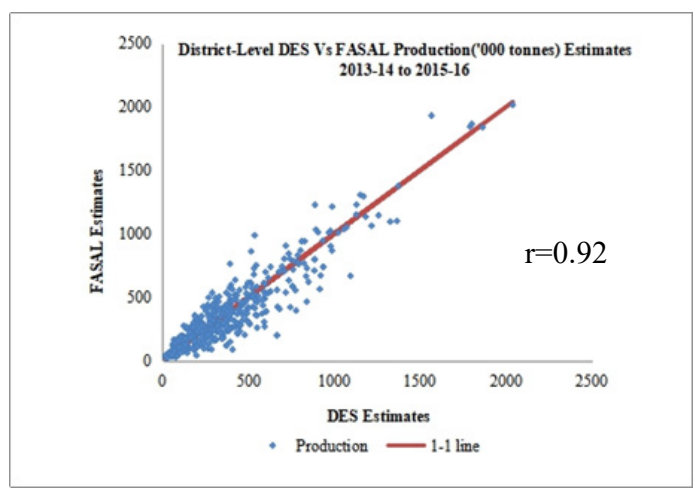

Figure 12. District-wise Production ('000 tonnes), DES and FASAL Estimates (2013-14 to 2015-16)

\section{SUMMARY AND CONCLUSION}

It was observed that the area and production estimates improved with improvement in the satellite resolution and number of ground truth data from 2016 onwards. It can be further improved by increasing the number of ground truth sites per district and preferred higher resolution satellite data for giving results at block and village level.

\section{ACKNOWLEDGEMENTS}

The wheat crop estimation work has been carried out under the FASAL (Forecasting Agricultural output using Space, Agrometeorology and Land based observations) of Department of Agriculture, Cooperation \& Farmers Welfare (DAC\&FW). The authors are thankful to the senior officials of DAC\&FW for their strong support and keen interest in the work. The ground truth data collected and expert knowledge provided for remote sensing data analysis by the officials of the State Agriculture Departments and State Remote Sensing Centres, are gratefully acknowledged. The satellite data provided by ISRO (Resourcesat $2 \&$ 2A), ESA (Sentinel 2), NASA (MODIS \& Landsat-8) and the weather data provided by IMD are thankfully acknowledged. Thanks, are also due to the Analysts of FASAL team, who carried out the annual wheat crop analysis. Thanks are also due to scientists of SAC(ISRO), who developed the procedures for crop estimation under FASAL project.

\section{REFERENCES}

Chaurasiya G., Saxena, Shalini, Tripathy, Rojalin, Chaudhary, K. N. and Ray, S. S. (2017) Semi Physical Approach for Sugarcane Yield Modelling with Remotely Sensed Inputs. Vayu Mandal 43(1):11-22

Dadhawal, V.K (1999) Remote Sensing applications for agriculture - Retrospective and Perspective. Proc. ISRS National Symp., Remote Sensing Applications Resources: Retrospective and Perspective. Jan. 19 - 21, 1999, Bangalore, pp $11-22$.

Ghosh, K., Balasubramanian, R., Bandopadhyay, S. Chattopadhyay, N., Singh, K.K. and Rathore, L.S., 2014, Development of crop yield forecast models under FASAL- a case study of kharif rice in West Bengal. J. Agro met., 16 (1), 1Kogan, F.N. (1997) Global drought watch from space. Bull. Am. Meteorol.Soc. 78, 621-636. 
Goswami, S. B, Saxena, Aruna and Bairagi, G. D (2012) Remote Sensing and GIS based wheat crop acreage estimation of Indore district, M.P. International Journal of Emerging Technology and Advanced Engineering, Volume 2, Issue 3, 2250-2459.

Hooda, R.S., Yadav, Manoj and Kalubarme, M.H. (2006) Wheat Production Estimation Using Remote Sensing data: An Indian Experience. ISPRS Archives XXXVI-8/W48 Workshop proceedings: Remote sensing support to crop yield forecast and area estimates.

NRSC (2006) National Land use and Land cover mapping using multi- temporal AWiFS data. NRSA/LULC/1:250K/2006-2. National Remote Sensing Centre. 39p.

Pandey, P. C., Dadhwal, V. K., Sahai, Baldev \& Kale, P. P. (1992) An optimal estimation technique for increasing the accuracy of crop forecasts by combining remotely sensed and conventional forecast results. International Journal of Remote Sensing. 13 (14): 2735-2741

Parihar, J. S. and Oza, S. R. (2006) FASAL: An integrated approach for crop assessment and production forecasting.
Proceedings of SPIE - The International Society for Optical Engineering 6411.

Ray, S. S. \& Neetu. 2017. Crop area estimation with Remote Sensing. In: J. Delincé (ed.), Handbook on Remote Sensing for Agricultural Statistics (Chapter 5). Handbook of the Global Strategy to improve Agricultural and Rural Statistics (GSARS): Rome. pp. 131-183.J.

Ray, S. S., Neetu, Manjunath, K. R. and Singh, K. K. (2016) Crop Production Forecasting using Space, Agro-meteorology and Land based Observations: Indian Experience. Presented in International seminar on approaches and methodologies for crop monitoring and production forecasting. 25 - 26 May 2016, Dhaka, Bangladesh.

Tripathy, R., Chaudhary, K.N., Nigam, R., Manjunath, K. R., Chauhan, P., Ray, S. S, and Parihar, J. S. (2014) Operational Semi-Physical Spectral-Spatial Wheat Yield Model Development. The International Archives of the Photogrammetry, Remote Sensing and Spatial Information Sciences, Volume XL 